\title{
Therapeutic options for resectable second lung tumor after previous pneumonectomy: a SEER database analysis
}

\author{
Xiangyang Yu, Shugeng Gao, Qi Xue, Fengwei Tan, Yushun Gao, Yousheng Mao, Dali Wang, Jun Zhao, \\ Yin Li, Feng Wang, Hong Cheng, Chenguang Zhao, Ding Yang, Juwei Mu \\ Department of Thoracic Surgery, National Cancer Center/National Clinical Research Center for Cancer/Cancer Hospital, Chinese Academy of \\ Medical Sciences and Peking Union Medical College, Beijing, China \\ Contributions: (I) Conception and design: X Yu, F Tan, Y Mao, J Mu; (II) Administrative support: S Gao, Q Xue, D Wang, J Zhao, J Mu; (III) \\ Provision of study materials or patients: X Yu, F Wang, H Cheng, C Zhao; (IV) Collection and assembly of data: X Yu, D Yang, Y Gao, Y Mao, D \\ Wang, J Zhao, Y Li; (V) Data analysis and interpretation: X Yu, F Zhang, J Zhao, Y Li; (VI) Manuscript writing: All authors; (VII) Final approval of \\ manuscript: All authors. \\ Correspondence to: Prof. Juwei Mu. Department of Thoracic Surgery, National Cancer Center/National Clinical Research Center for Cancer/Cancer \\ Hospital, Chinese Academy of Medical Sciences and Peking Union Medical College, Beijing 100021, China. Email: mujuwei@cicams.ac.cn.
}

Background: Therapeutic options for patients with second lung tumor (SLT) after previous pneumonectomy for lung cancer are sparsely reported and controversial. This study aims to compare the short- and long-term outcomes of different treatment patterns in patient with resectable postpneumonectomy SLT.

Methods: Patients received previous pneumonectomy and subsequently occurred resectable SLT were extracted from the Surveillance, Epidemiology, and End Results (SEER) database [1998-2016]. Treatment related mortality was compared using the Pearson chi-square test. Univariate and multivariate Cox regression analyses were performed to identify the independent prognostic factors for cancer-specific survival (CSS) and overall survival (OS).

Results: Ninety-nine patients met the selection criteria with 5-year CSS and OS rates of $60.8 \%$ and $53.7 \%$, respectively: 23 patients received no lung resection (nLR) and 76 patients received lung resection (LR). There was no statistically significant difference between $\mathrm{nLR}$ group and LR group in both treatment related mortality $(0.0 \%$ vs. $2.6 \%, \mathrm{P}=0.432)$, CSS (58.3\% vs. $61.7 \%, \mathrm{P}=0.633)$ and $\mathrm{OS}(55.3 \%$ vs. $53.3 \%$, $\mathrm{P}=0.635)$. Patients with subsequent adenocarcinoma $(\mathrm{P}=0.001)$ and smaller tumor size of $\mathrm{SLT}(\mathrm{P}<0.001)$ were more likely to receive LR treatment. In the LR subgroup analysis, patients received sublobar resection (SLR) had better CSS [hazard ratio (HR): 0.381, 95\% confidence interval (CI): 0.176-0.827, P=0.030] and OS (HR: $0.562,95 \%$ CI: $0.287-1.100, \mathrm{P}=0.051)$ than those received lobectomy.

Conclusions: SLR or non-surgical resection is reasonable therapeutic option for patients with resectable SLT after previous pneumonectomy to achieve long-term survival, with acceptable treatment related mortality.

Koywords! Lung cancer; pneumonectomy; contralateral lung tumor; survival

Submitted Sep 05, 2020. Accepted for publication Nov 04, 2020.

doi: 10.21037/apm-20-1781

View this article at: http://dx.doi.org/10.21037/apm-20-1781

\section{Introduction}

On April 1933, Evarts A. Graham performed the first successful one-stage pneumonectomy in a gynecologist with pulmonary squamous cell carcinoma (pathological
T2N1M0, stage IIB) who survived for nearly 30 years, as well as the first lung resection (LR) in treatment of lung cancer (1). However, because of a high postoperative complication rate (3.4-54.0\%) and mortality (3.0-26.0\%), one-sided entire lung removal is recommended only for 
patients with centrally-located non-small cell lung cancer (NSCLC), if a margin-negative resection can not be achieved by lung-sparing surgical technique (2-6). Even though, pneumonectomy still accounts for approximately $10 \%$ of all lung cancer resections (7).

Patients who have been successfully removed for an initial primary lung cancer remain a continued risk for development of a second primary lung tumor or intrapulmonary metastasis (1.0-2.0\% risk per patient per year) $(8,9)$. Repetitive LR with lymph node evaluation for second lung tumor (SLT) can offer a chance of long-term survival (9). Nevertheless, for patients who have underwent one-sided pneumonectomy, respiratory management during contralateral lung surgery is a technical difficulty because of the unfulfillable one-lung ventilation $(4,5)$. Moreover, second LR after previous pneumonectomy will bring nonnegligible risk of operative complication rate $(0.0-77.7 \%)$ and mortality (0.0-33.3\%), mainly owing to the respiratory reserve, physical status, and pathophysiological changes (5,10-18). Of note, several retrospective series have suggested that local non-surgical treatments, including stereotactic body radiation therapy (SBRT), conventional radiotherapy (CRT), interventional therapy (IVT) etc., can not only ensure the treatment related safety, but also bring long-term survival in patients with postpneumonectomy SLT (4,19-26). Although the respective advantages and survival outcomes of non-surgical treatment and surgical resection for SLT arising postpneumonectomy have been described detailedly in the published literatures, the comparative analysis between different therapeutic patterns remain unreported $(17,27)$.

In this population-based study, we sought to conduct the comparison of short- and long-term outcomes between different therapeutic options for resectable contralateral lung tumor after prior pneumonectomy. In addition, the potential factors associated with the therapeutic options and the independent prognostic factors for cancer-specific survival (CSS) and overall survival (OS) were identified. We present the following article in accordance with the STROBE reporting checklist (available at http://dx.doi. org/10.21037/apm-20-1781).

\section{Methods}

\section{Patients selection}

Patients who underwent previous pneumonectomy (surgery primary site codes: 40, 50-56, 65-66, 70) for lung cancer [International Classification of Disease for Oncology, 3rd edition (ICD-O-3): lung and bronchus] and subsequently occurred a contralateral lung tumor between 1998 and 2016 were extracted from the Surveillance, Epidemiology, and End Results (SEER) database (November 2018 submission) by using SEER*Stat 8.3.6.1. Thereafter, patients with cancerdirected surgery codes for SLT corresponding to "surgery performed", "recommended but not performed", and "recommended" records were identified as resectable cases and included into the study cohort. In addition, patients with incomplete follow-up information and tumor staging were excluded. The selection flow is illustrated in Figure 1. This retrospective study based on the National Cancer Institute's SEER database was approved by the institutional review board at Cancer Hospital, Chinese Academy of Medical Sciences and Peking Union Medical College (No. NCC201802006) and individual consent for this retrospective analysis was waived. All authors stated that the study conformed to the provisions of the Declaration of Helsinki (as revised in 2013).

\section{Covariates and endpoints}

The continuous variable of age at SLT diagnosis was divided into two brackets ( $\leq 60 />60$ years old). According to the modified classification criteria for SLT proposed by the American College of Chest Physicians (ACCP) Guidelines, all histologically different SLTs were defined as metachronous. For histologically same SLTs, the SLTs were also defined as metachronous if the interval between initial pneumonectomy and SLTs has lasted 4 years or longer without systemic metastases (28). In addition, we recategorized the tumor-node-metastasis (TNM) staging documented in the SEER database according to the eighth edition of the TNM classification for lung cancer. No lung resection (nLR) included chemotherapy (CT) alone, radiotherapy (RT) alone, and IVT. Patients received sublobar resection [SLR, including non-anatomical wedge resection (WR) and anatomical segmentectomy (S)] or lobectomy were grouped into LR.

Survival time was calculated from the date of SLT diagnosis to the date of death or the last follow-up. Only deaths caused by lung cancer were recorded as censored cases in the CSS analysis, but the OS analysis included any cause of death. Treatment related mortality was defined as any death within 30 days after the treatment for SLT. 


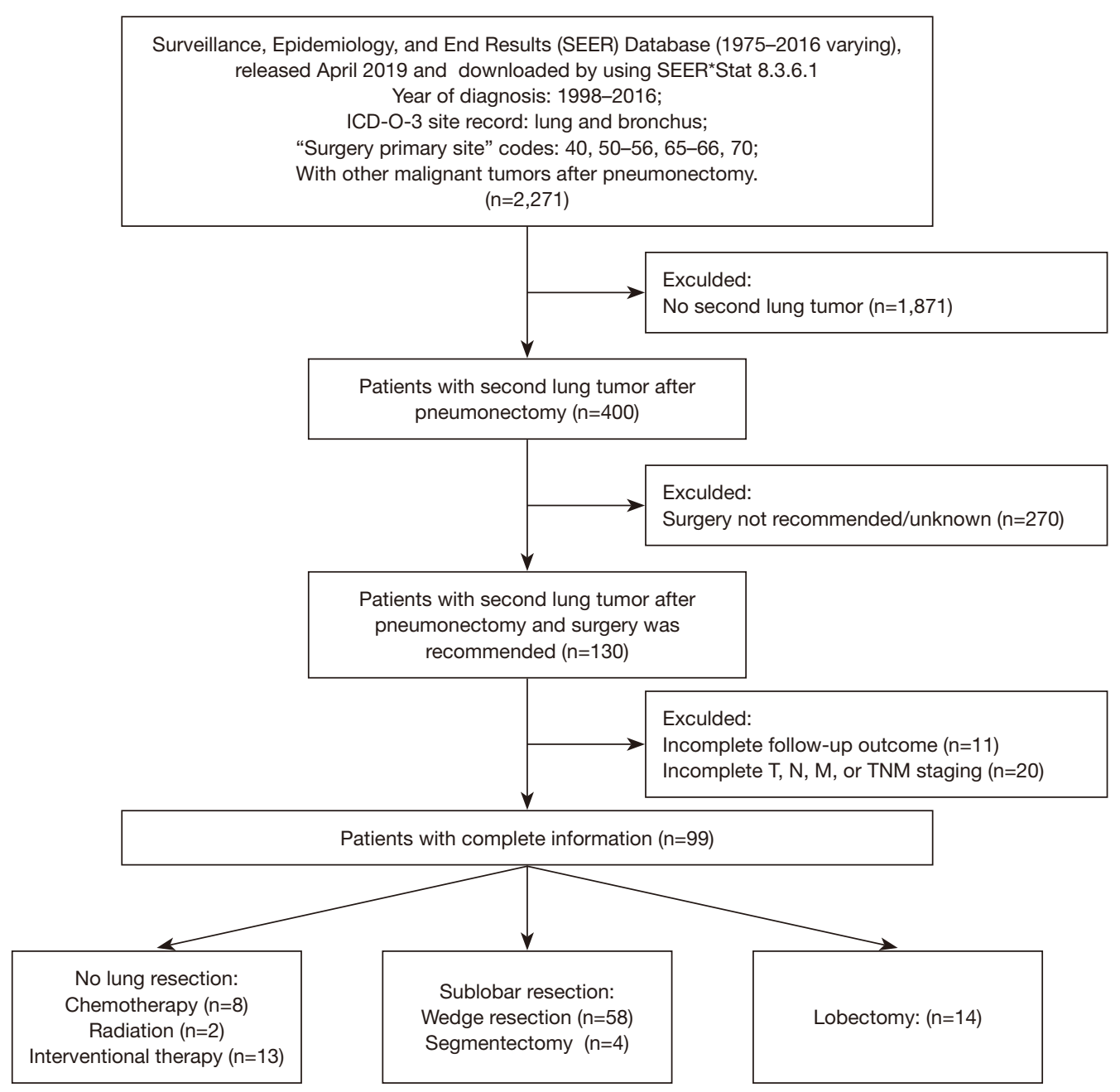

Figure 1 Flowchart of patient selection from the SEER database. SEER, Surveillance, Epidemiology, and End Results; ICD-O-3, International Classification of Disease for Oncology, $3 \mathrm{rd}$ edition; TNM, tumor-node-metastasis.

\section{Statistical analysis}

The optional cutoff values for interval time were determined by using the $\mathrm{X}$-tile software (version 3.6.1, copyright Yale University 2003). Continuous variables were presented as mean \pm standard deviation $(\mathrm{SD})$ and compared by the student's $t$-test, and categorical variables were showed as numbers (frequency percentages) and compared using the Pearson chi-square test or Fisher's exact test. Cox regression model was applied to identify the independent prognostic factors associated with CSS and OS in both univariate and multivariate analyses.

All above statistical analyses were performed by the SPSS 25.0 software (IBM SPSS, Armonk, NY, USA) and all P value less than 0.05 at two sides was considered statistically significant difference. Additionally, the Kaplan-Meier survival curves were plotted by using the Graphpad Prism software (version 7.0).

\section{Results}

\section{Patient demographics}

A total of 400 patients ( 400 of 10,801, 3.7\%) who underwent previous pneumonectomy occurred a contralateral lung tumor, but surgical resection was not recommended for most of the patients (67.5\%). Finally, only 99 patients met the selection criteria, including 23 patients received nLR treatment and 76 patients underwent LR treatment (Table 1 and Figure 1). The median interval time between prior 
Table 1 Comparison of clinicopathological variables between the nLR group and LR group

\begin{tabular}{|c|c|c|c|}
\hline Variables & $\mathrm{nLR}(\mathrm{n}=23)$ & $\operatorname{LR}(n=76)$ & $P$ value \\
\hline Age at SLT (years), mean \pm SD & $66.22 \pm 12.19$ & $64.13 \pm 9.52$ & 0.392 \\
\hline Female sex, $\mathrm{n}(\%)$ & $8(34.8)$ & $29(38.2)$ & 0.962 \\
\hline Race, n (\%) & & & 0.263 \\
\hline Black & $1(4.3)$ & $3(3.9)$ & \\
\hline Other & $2(8.7)$ & $1(1.3)$ & \\
\hline Interval time between pneumonectomy and SLT (months), mean \pm SD & $53.11 \pm 37.30$ & $40.69 \pm 37.95$ & 0.170 \\
\hline Left-sided pneumonectomy, n (\%) & $15(65.2)$ & $48(63.2)$ & 0.857 \\
\hline Adenocarcinoma & $8(34.8)$ & $48(63.2)$ & \\
\hline Grade of pneumonectomy, n (\%) & & & 0.790 \\
\hline I, well & $1(4.3)$ & $3(3.9)$ & \\
\hline II, moderately & $8(34.8)$ & $35(46.1)$ & \\
\hline III, poorly & $8(34.8)$ & $25(32.9)$ & \\
\hline IV, undifferentiated & $1(4.3)$ & $4(5.3)$ & \\
\hline Unknown & $5(21.7)$ & $9(11.8)$ & \\
\hline Radiation with pneumonectomy, n (\%) & $7(30.4)$ & $21(28.0)$ & 0.821 \\
\hline IV & $0(0.0)$ & $4(5.3)$ & \\
\hline Histology of SLT, n (\%) & & & 0.001 \\
\hline Squamous cell carcinoma & $11(47.8)$ & $18(23.7)$ & \\
\hline Adenocarcinoma & $3(13.0)$ & $43(56.6)$ & \\
\hline Neuroendocrine tumor & $1(4.3)$ & $5(6.6)$ & \\
\hline Adenosquamous carcinoma & $0(0.0)$ & $2(2.6)$ & \\
\hline Other/unknown & $8(34.8)$ & $8(10.5)$ & \\
\hline \multicolumn{4}{|l|}{ Grade of SLT } \\
\hline I, well & $0(0.0)$ & $9(11.8)$ & 0.019 \\
\hline II, moderately & $7(30.4)$ & $24(31.6)$ & \\
\hline III, poorly & $6(26.1)$ & $29(38.2)$ & \\
\hline
\end{tabular}

Table 1 (continued) 
Table 1 (continued)

\begin{tabular}{|c|c|c|c|}
\hline Variables & $\mathrm{nLR}(\mathrm{n}=23)$ & $\operatorname{LR}(n=76)$ & $P$ value \\
\hline IV, undifferentiated & $0(0.0)$ & $2(2.6)$ & \\
\hline Unknown & $10(43.5)$ & $12(15.8)$ & \\
\hline Tumor size of SLT, mean \pm SD & $45.72 \pm 19.96$ & $27.85 \pm 13.77$ & $<0.001$ \\
\hline TNM staging of SLT, $n(\%)$ & & & 0.160 \\
\hline I & $14(60.9)$ & $55(72.4)$ & \\
\hline II & $4(17.4)$ & $6(7.9)$ & \\
\hline III & $5(21.7)$ & $10(13.2)$ & \\
\hline IV & $0(0.0)$ & $5(6.6)$ & \\
\hline Type of SLT, n (\%) & & & 0.212 \\
\hline Metastasis & $6(26.1)$ & $33(43.4)$ & \\
\hline Metachronous & $17(73.9)$ & $43(56.6)$ & \\
\hline \multicolumn{4}{|l|}{ Treatment of SLT, n (\%) } \\
\hline CT & $8(34.8)$ & - & \\
\hline RT & $2(8.7)$ & - & \\
\hline IVT & $13(56.5)$ & - & \\
\hline WR & - & $58(76.3)$ & \\
\hline S & - & $4(5.3)$ & \\
\hline Lobectomy & - & $14(18.4)$ & \\
\hline
\end{tabular}

$\mathrm{nLR}$, no lung resection; LR, lung resection; SD, standard deviation; SLT, second lung tumor; CT, chemotherapy; TNM, tumor-nodemetastasis; RT, radiotherapy; IVT, interventional therapy; WR, wedge resection; S, segmentectomy.

pneumonectomy and SLT was 35.57 (range, 1.01-183.63) months, and the majority of the SLTs were metachronous (60.6\%). In nLR group, most of the patients (13 of 23, $56.5 \%$ ) received interventional ablation treatment and $34.8 \%$ of the patients were given systematic CT alone. Among patients who underwent additional LR, 14 patients received lobectomy and 62 received SLR (including WR =58, S =4).

\section{Factors associated with therapeutic options}

Therapeutic options for resectable SLTs after previous pneumonectomy were not interfered with the initial clinicopathological characteristics. Patients in LR group were more likely to be subsequent adenocarcinoma $(\mathrm{P}=0.001)$, to have a smaller tumor size of SLT $(\mathrm{P}<0.001$; Table 2). In addition, compared with patients received lobectomy for SLT, those received SLR were more likely to be white race $(\mathrm{P}=0.027)$, to have longer interval time $(\mathrm{P}=0.043)$ and early stage (stage I/II, $\mathrm{P}=0.037$; Table $\mathrm{S} 1$ ).

\section{Survival outcomes}

Overall, only 2 patients (2.0\%) died with 30 days after the treatment for SLT. There was no difference in treatment related mortality between $\mathrm{nLR}$ group and LR group $(0.0 \%$ vs. $2.6 \%, \mathrm{P}=0.432)$. The median follow-up time for the whole patients was 60 (range, 1-219) months with 5-year CSS and OS rates of $60.8 \%$ and $53.7 \%$, respectively.

Separately, there was no statistically significant difference between $\mathrm{nLR}$ and LR in both CSS $(\mathrm{P}=0.633)$ and OS $(\mathrm{P}=0.635$; Table 2). In univariate analyses, sex, interval time between pneumonectomy and SLT, TNM staging of SLT, and type of SLT showed significant associations both with CSS and OS (all $\mathrm{P}<0.05$; Table 2). After adjusting these potential predictors in multivariate Cox regression models, female $(\mathrm{P}=0.006$ and 0.001 , respectively; Figure $2 A, B)$, interval time greater than 53 months $(\mathrm{P}=0019$ and 0.003 , respectively; Figure $2 C, D$ ), and early stage of SLT (III; $\mathrm{P}<0.001$ and $<0.001$, respectively; Figure $2 E, F)$ were 
Table 2 Univariate Cox regression analysis of the whole patients with resectable SLT after previous pneumonectomy

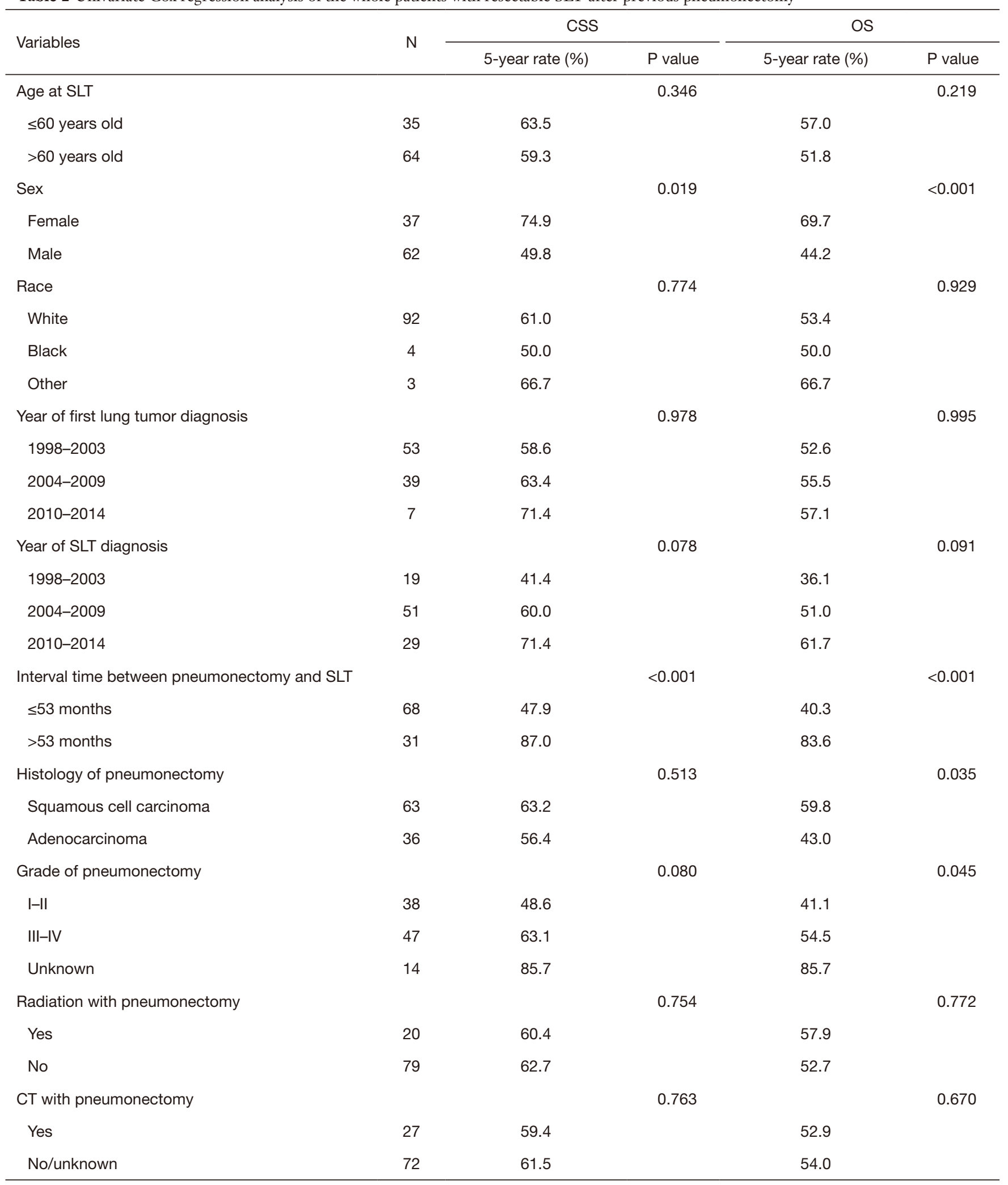

Table 2 (continued) 
Table 2 (continued)

\begin{tabular}{|c|c|c|c|c|c|}
\hline Variables & $\mathrm{N}$ & \multicolumn{2}{|c|}{ CSS } & \multicolumn{2}{|c|}{ OS } \\
\hline TNM staging of pneumonectomy & & & 0.133 & & 0.691 \\
\hline$|-| \mid$ & 55 & 67.3 & & 57.4 & \\
\hline III-IV & 44 & 52.7 & & 49.0 & \\
\hline Right & 63 & 63.2 & & 59.8 & \\
\hline Left & 36 & 56.4 & & 43.0 & \\
\hline Tumor size of SLT & & & 0.883 & & 0.251 \\
\hline$\leq 30 \mathrm{~mm}$ & 65 & 61.4 & & 51.6 & \\
\hline Squamous cell carcinoma & 46 & 53.8 & & 47.0 & \\
\hline Adenocarcinoma & 29 & 60.0 & & 51.0 & \\
\hline Neuroendocrine tumor & 2 & 33.3 & & 33.3 & \\
\hline Adenosquamous carcinoma & 6 & 100.0 & & 50.0 & \\
\hline Other/unknown & 16 & 80.4 & & 75.0 & \\
\hline Grade of SLT & & & 0.411 & & 0.610 \\
\hline$|-I|$ & 40 & 57.0 & & 46.6 & \\
\hline III-IV & 37 & 69.9 & & 61.4 & \\
\hline Metastasis & 39 & 45.7 & & 39.3 & \\
\hline Metachronous & 60 & 70.1 & & 62.9 & \\
\hline Treatment of SLT & & & 0.633 & & 0.635 \\
\hline $\mathrm{nLR}$ & 23 & 58.3 & & 55.3 & \\
\hline LR & 76 & 61.7 & & 53.3 & \\
\hline
\end{tabular}

SLT, second lung tumor; CSS, cancer-specific survival; OS, overall survival; CT, chemotherapy; TNM, tumor-node-metastasis; nLR, no lung resection; LR, lung resection.

identified as strong predictors for better CSS and OS in SLT after previous pneumonectomy (Table 3).

In the LR subgroup analysis, the SLR group had better CSS in statistics $(\mathrm{P}=0.030$, Figure $3 A)$, and better OS in trend $(\mathrm{P}=0.051$, Figure $3 B)$ than the lobectomy group.
Additionally, in the univariate analyses of OS, sex, interval time, TNM staging of SLT, radiation with SLT, CT with SLT, type of SLT were also identified as independent predictors (Table S2). Similar results (except for the sex variable) were obtained from the univariate analyses of CSS 
A

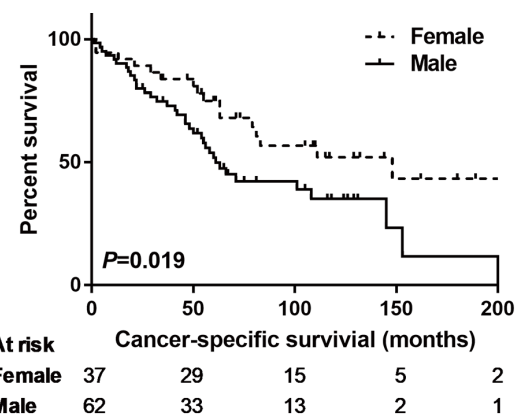

C

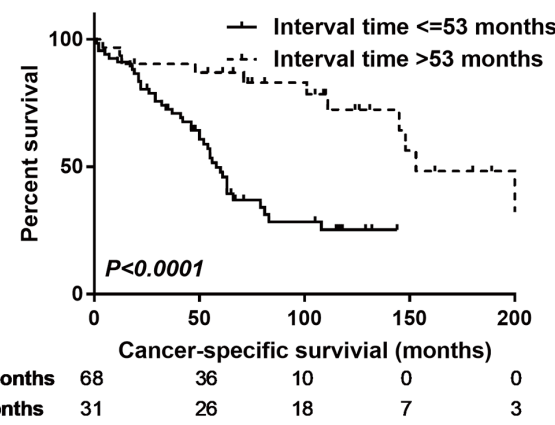

$\mathrm{E}$

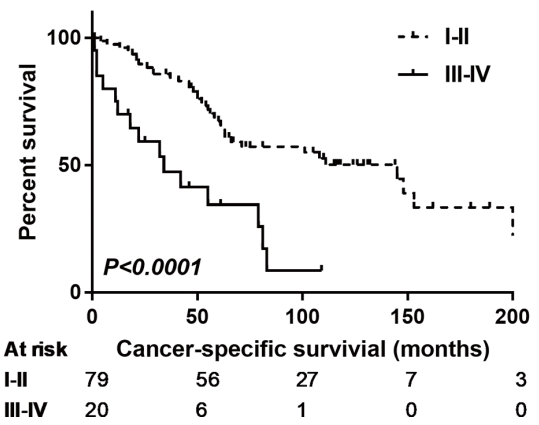

B
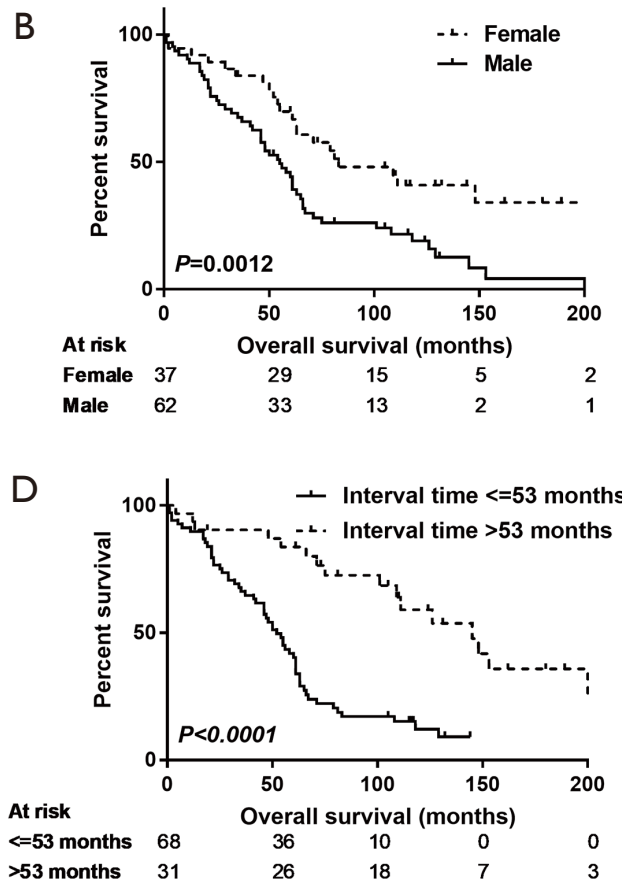

F

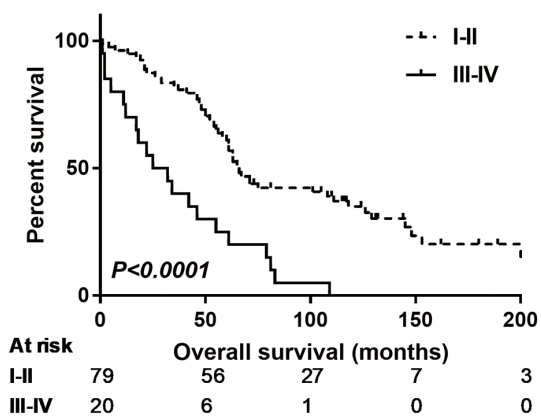

Figure 2 CSS (A,C,E) and OS (B,D,F) of the whole patients based on sex, interval time between pneumonectomy and SLT, and TNM staging of SLT. CSS, cancer-specific survival; OS, overall survival; SLT, second lung tumor; TNM, tumor-node-metastasis.

(Table S2). The above variables were further examined in the multivariate Cox regression models (Table S3). Interval time greater than 53 months $(\mathrm{P}=0.003$ for CSS; $\mathrm{P}=0.001$ for OS), early stage of SLT (I-II; $\mathrm{P}=0.026$ for CSS; $\mathrm{P}=0.011$ for OS), CT with SLT ( $\mathrm{P}=0.008$ for CSS, Figure 3C; $\mathrm{P}=0.001$ for OS, Figure 3D), and SLR for SLT ( $\mathrm{P}=0.015$ for CSS; and $\mathrm{P}=0.093$ for $\mathrm{OS}$ ) were significantly associated with longer survival, whereas the female was a significant predictor only for better OS $(\mathrm{P}=0.003)$.

\section{Discussion}

In this population-based analysis, patients with onesided entire lung removal for initial lung cancer showed a $3.7 \%$ risk of having a SLT, with median interval time to development longer than 3 years. Compared with those received non-surgical treatment, patients received secondary LR had similar treatment-related mortality and long-term survival. Additionally, patients in SLR subgroup showed longer CSS in statistics and better OS in trend than those in lobectomy subgroup.

According to the latest National Cancer Comprehensive Network and ACCP Guidelines for NSCLC, if patients who are able to withstand definitive local therapy, lung-sparing resection is recommended as a primary therapeutic option for SLT to obtain long-term survival $(2,28)$. Even though, the proportion of patients received additional LR for SLT following a surgical resection 
Table 3 Multivariate Cox regression analysis of the whole patients with resectable SLT after previous pneumonectomy

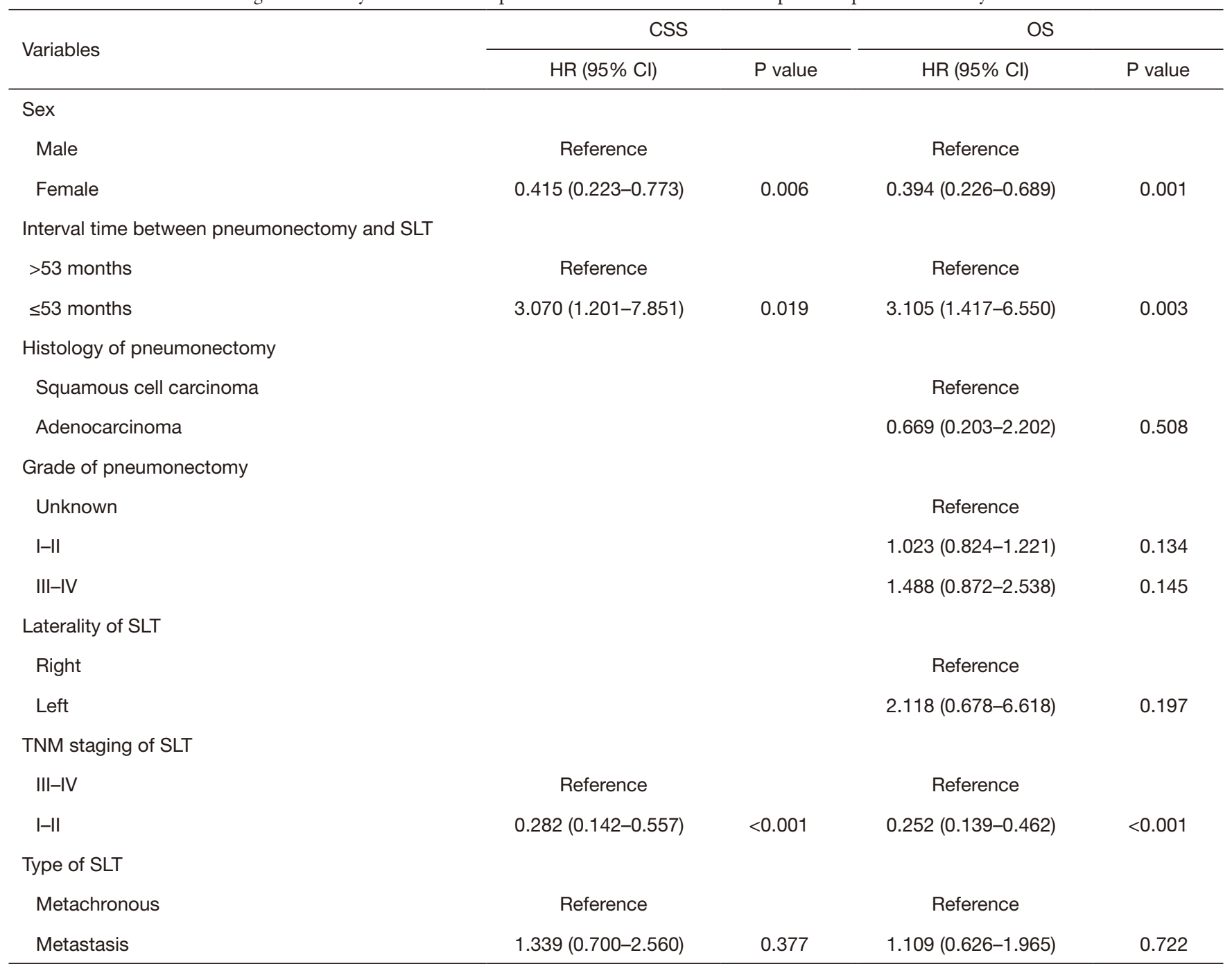

SLT, second lung tumor; CSS, cancer-specific survival; OS, overall survival; HR, hazard ratio; Cl, confidence interval; TNM, tumor-nodemetastasis.

of the initial lung cancer remains low, because the therapeutic options of these patients are affected by the patients' respiratory reserve, physical status, clinical stage, and pathophysiological changes etc. Zhang et al. stated that about $17.3 \%(1,171$ of 6,751$)$ of the patients who underwent previous lobectomy or bilobectomy were given the surgical treatment for SLT (9). However, up to date, only approximately 169 cases received subsequent LR on a single remaining lung were reported in the literatures (Table 4). Grodzki et al. reported that the percentage of patients had the chance of secondary LR for postpneumonectomy SLT was $18.0 \%$ (18 of 100) in their single center (12). Another study based on the SEER database revealed that about $13.7 \%$ of patients $(63 / 459)$ who underwent previous pneumonectomy for initial lung cancer went on to secondary LR during a 25 -year period, which was the largest series in the published literatures (5). Similar proportion (76 of 400, 19.0\%) was observed in present study as well. Although secondary resection for SLT arising postpneumonectomy can bring acceptable long-term survival (5-year OS rate: $25.0-66.6 \%$ ), the high perioperative morbidity $(0.0-77.7 \%)$ and mortality $(0.0$ $33.3 \%$ ) are not negligible (Table 4) (5,10-18). Before 2009, surgical resection was performed in all reported patients with postpneumonectomy SLT, including $80 \mathrm{WRs}(77.7 \%), 16 \mathrm{Ss}$ (15.5\%), and 7 lobectomies (6.8\%). However, in the recent 

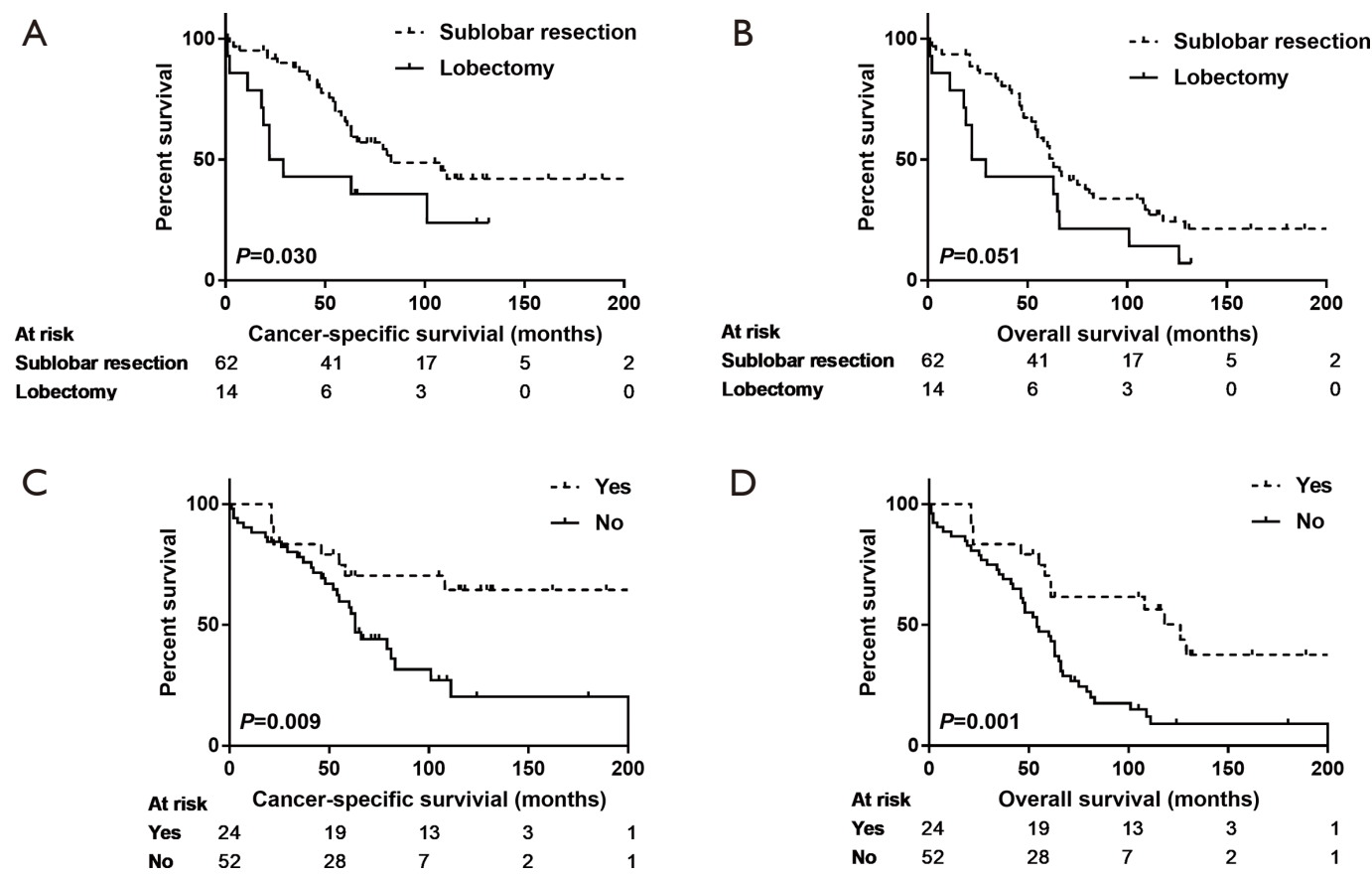

Figure 3 CSS (A,C) and OS (B,D) of the patients who underwent LR treatment based on CT with SLT and surgical procedure of SLT. CSS, cancer-specific survival; OS, overall survival; LR, lung resection; CT, chemotherapy; SLT, second lung tumor.

10 years, most of the patients $(296 / 365,81.1 \%)$ received non-surgical therapy, i.e., CT, RT, and IVT (Table 4).

In recent years, evidence from several larger study series indicated that, because of a good local control and low toxicity, SBRT can be a reasonable option for medically inoperable patients with early-stage lung cancer $(2,28)$. The early literature on SBRT for postpneumonectomy SLT was reported by Haasbeek et al. in the year of 2019 (Table 4) (26). Although half of the 15 cases from two centers accompanied with severe chronic obstructive pulmonary disorder (COPD), only two patients occurred grade $\geq 3$ toxicity and the actuarial 2-year rates of local control and OS were 91\% and $100 \%$, respectively (26). Subsequently, his colleagues, Senthi et al., updated the late toxicity after long-term follow-up, and supplemented the additional outcomes of modern RT technique, including conventional RT $(\mathrm{n}=1)$, hypofractionated RT $(\mathrm{n}=6)$, and SBRT $(\mathrm{n}=20)(23)$. Similarly, only three patients experienced grade 3 or higher radiation pneumonitis and the actuarial 3-year rates of local control and OS were $92 \%$ and $63.0 \%$, respectively (23). What's more, no RT related death was observed in the above two retrospective studies $(23,26)$. Recently, the largest cohort of 122 patients who underwent RT for inoperable postpneumonectomy SLT retired from the SEER database was published by Ayub et al., and the mortality within 90-day after RT was $4.9 \%$ and a median OS for patients receiving RT was 25.0 months (3-year OS rate, 34\%) (4).

Another therapeutic modality, IVT (including thermal ablation and cryotherapy) is also recommended for patients with medically inoperable early-stage and multiple lung cancer to achieve definitive local therapy $(2,28)$. Nevertheless, up to now, only 27 patients with postpneumonectomy SLT received thermal ablation treatment in the published literatures $(24,25)$. Taken together, the treatment related complications included mild parenchymal hemorrhages during ablation $(n=5)$, pneumothoraces $(n=10)$, pulmonary infection $(n=1)$, and limited hemoptysis $(\mathrm{n}=2)$; and two procedural deaths $(2 / 27$, $7.4 \%)$ occurred $(24,25)$. In addition, the 2 - and 3 -year OS rate after ablation for postpneumonectomy SLT, reported in the above two pilot studies, were $71.4 \%$ and $30.0 \%$, respectively, which was consistent with the present study based on SEER database (2-year OS rate, 69.2\%; and 3-year OS rate, $44.0 \%)$. Of note, according to the horizontal comparison of these contemporaneous literatures, local recurrence of patients with interventional ablation treatment (2-year local recurrence rate, $5.0-80.4 \%)$ was higher than that of those with RT (2-year local recurrence 
Table 4 Published data of therapeutic options for SLT after previous pneumonectomy

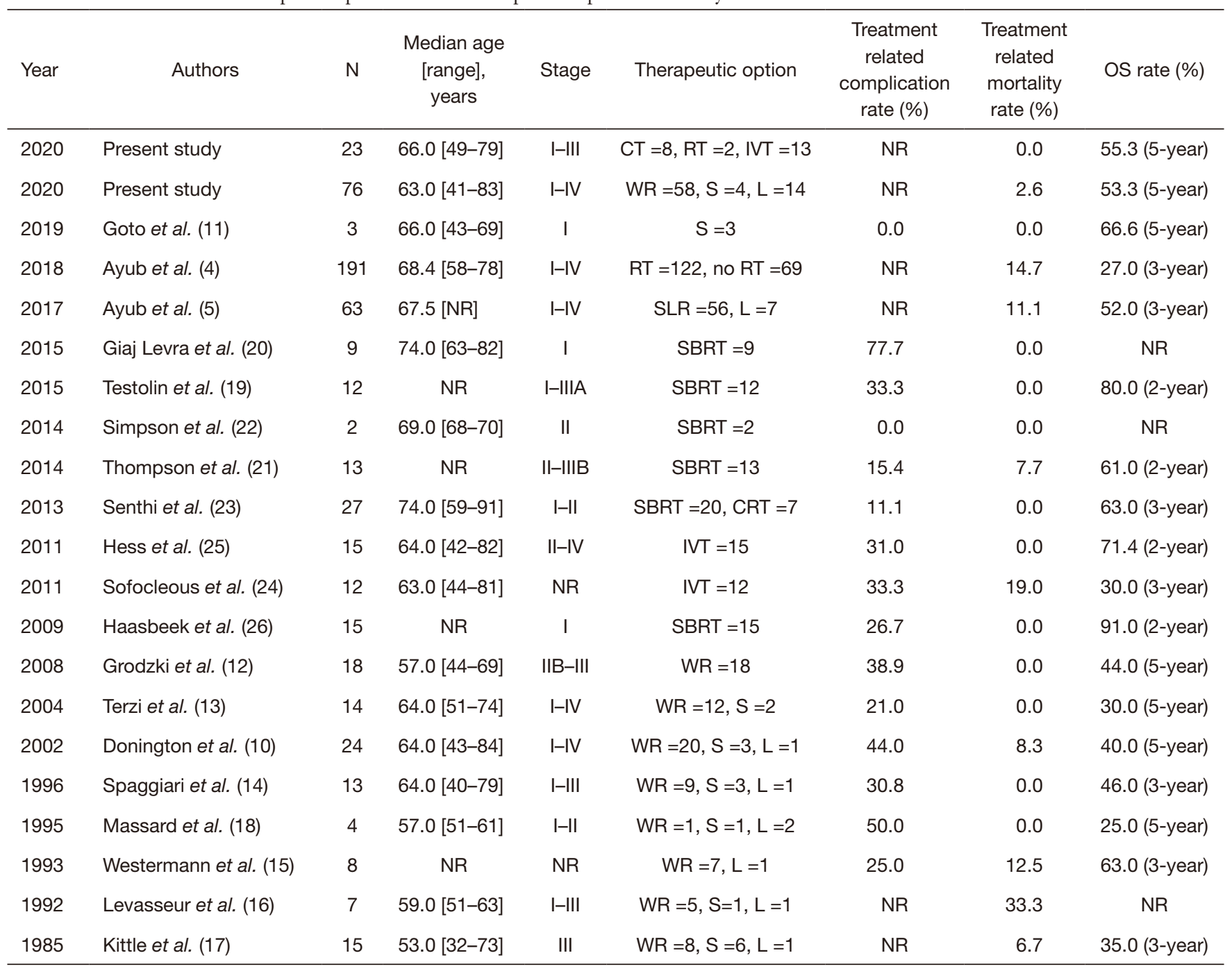

SLT, second lung tumor; OS, overall survival; NR, no reported; CT, chemotherapy; RT, radiotherapy; IVT, interventional therapy; WR, wedge resection; S, segmentectomy; L, lobectomy; SLR, sublobar resection; SBRT, stereotactic body radiation therapy; CRT, conventional radiotherapy.

rate, $0.0-35.5 \%)$. To sum up, RT or interventional ablation treatment may be attractive and safe therapeutic option for patients with postpneumonectomy SLTs, especially for those with medically inoperable SLT.

Much of the nonrandomized clinical data on patients with resectable SLT after previous lobectomy or bilolobectomy demonstrated that surgical resection plus lymph nodes dissection, no matter SLR or lobectomy, was associated with significantly longer survival compared with non-surgery $(2,9,28)$. Similarly, through reviewing the two largest series on postpneumonectomy SLT extracted from the SEER database and all reported by Ayub et al. (Table 4), we found that patients with resectable SLT receiving surgical resection had higher treatment related mortality (12.7\% vs. $4.9 \%)$ and 3 -year OS rate $(54.0 \%$ vs. $34.0 \%)$ than those with unresectable SLT who receiving RT $(4,5)$. However, to our knowledge, there is no special focus on the comparison between non-surgery and surgery for patients with resectable SLT after previous pneumonectomy. In the present study on patients with resectable postpneumonectomy SLT, compared with those received non-surgical treatment, patients received secondary LR had 
similar treatment-related mortality and long-term survival. We speculate that patients recommended for surgery for SLT in the SEER database may have satisfactory pulmonary function reserve, good performance status, and early-stage SLT; therefore, they could well tolerate the treatment related complications to obtain long-term survival. However, surgical specimens could help oncologists to more accurately evaluate the genetic mutations and tumor microenvironment to guide the subsequent targeted therapy and immunotherapy $(2,28)$. For the extent of resection, almost all literatures on patients received surgery for postpneumonectomy SLT demonstrated that patients in SLR group had a higher OS than those in lobectomy group in trend (Table 4). Similar result was verified in this population-based study, and the significant difference was firstly found.

Undeniably, our study has several limitations. First, this retrospective, small sample cohort study is abstracted from a national database and the year of diagnosis spans nearly 20 years, which inevitably cause selection bias. Second, the main factors, such as pulmonary function reserve, performance status, postpneumonectomy complications, location of SLT (central or peripheral) et al., that may effect the surgeon's intention to select therapeutic options are not available within the SEER database. Third, individual RT techniques, doses and fractions, CT regimens, and interventional ablation techniques, which may affect the therapeutic efficacy, are not documented in the SEER database as well. Fourth, limited by the number of patients who underwent CT alone, or RT alone for postpneumonectomy SLT, the outcomes of the different therapeutic options are not further compared.

\section{Conclusions}

Aggressive treatment, no matter surgical resection or not, should be considered for patients with resectable SLT after previous pneumonectomy. Moreover, more accurate diagnosis of pathology, advanced molecular and genomic detections, and long-term survival can be obtained with limited resection, especially in patients with early-stage disease (I-II) and interval time to development of SLT longer than 4 years.

\section{Acknowledgments}

Funding: The preparation, English editing and publication of this manuscript were supported by the National Key
R\&D Plan (No. 2017YFC1308700), the Ministry of Science and Technology of the People's Republic of China.

\section{Footnote}

Reporting Checklist: The authors have completed the STROBE reporting checklist. Available at http://dx.doi. org/10.21037/apm-20-1781

Peer Review File: Available at http://dx.doi.org/10.21037/ apm-20-1781

Conflicts of Interest: All authors have completed the ICMJE uniform disclosure form (available at http://dx.doi. org/10.21037/apm-20-1781). The authors have no conflicts of interest to declare.

Ethical Statement: The authors are accountable for all aspects of the work in ensuring that questions related to the accuracy or integrity of any part of the work are appropriately investigated and resolved. This retrospective study based on the SEER database was approved by the Surveillance Research Program in National Cancer Institute's Division of Cancer Control and Population Sciences (DCCPS) (reference number: 12101-Nov2018). This retrospective study based on the National Cancer Institute's SEER database was approved by the institutional review board at Cancer Hospital, Chinese Academy of Medical Sciences and Peking Union Medical College (No. NCC201802006) and individual consent for this retrospective analysis was waived. All authors stated that the study conformed to the provisions of the Declaration of Helsinki (as revised in 2013).

Open Access Statement: This is an Open Access article distributed in accordance with the Creative Commons Attribution-NonCommercial-NoDerivs 4.0 International License (CC BY-NC-ND 4.0), which permits the noncommercial replication and distribution of the article with the strict proviso that no changes or edits are made and the original work is properly cited (including links to both the formal publication through the relevant DOI and the license). See: https://creativecommons.org/licenses/by-nc-nd/4.0/.

\section{References}

1. Graham EA, Singer JJ. Successful removal of an entire lung for carcinoma of the bronchus. CA Cancer J Clin 
1974;24:238-42.

2. Ettinger DS, Wood DE, Aggarwal C, et al. NCCN guidelines insights: non-small cell lung cancer, version 1.2020. J Natl Compr Canc Netw 2019;17:1464-72.

3. Petrella F, Spaggiari L. Therapeutic options following pneumonectomy in non-small cell lung cancer. Expert Rev Respir Med 2016;10:919-25.

4. Ayub A, Rehmani S, Al-Ayoubi AM, et al. Radiation therapy improves survival for unresectable postpneumonectomy lung tumors. J Surg Res 2018;227:60-6.

5. Ayub A, Rehmani SS, Al-Ayoubi AM, et al. Pulmonary resection for second lung cancer after pneumonectomy: a population-based study. Ann Thorac Surg 2017;104:1131-7.

6. Renaud S, Falcoz PE, Olland A, et al. Is radiofrequency ablation or stereotactic ablative radiotherapy the best treatment for radically treatable primary lung cancer unfit for surgery? Interact Cardiovasc Thorac Surg 2013;16:68-73.

7. Hancock J, Rosen J, Moreno A, et al. Management of clinical stage IIIA primary lung cancers in the National Cancer Database. Ann Thorac Surg 2014;98:424-32; discussion 432.

8. Thakur MK, Ruterbusch JJ, Schwartz AG, et al. Risk of second lung cancer in patients with previously treated lung cancer: analysis of Surveillance, Epidemiology, and End Results (SEER) data. J Thorac Oncol 2018;13:46-53.

9. Zhang R, Wang G, Lin Y, et al. Extent of resection and lymph node evaluation in early stage metachronous second primary lung cancer: a population-based study. Transl Lung Cancer Res 2020;9:33-44.

10. Donington JS, Miller DL, Rowland CC, et al. Subsequent pulmonary resection for bronchogenic carcinoma after pneumonectomy. Ann Thorac Surg 2002;74:154-8; discussion 158-9.

11. Goto H, Mun M, Mori S, et al. Thoracoscopic partial lung resection following pneumonectomy: a report of three cases. J Cardiothorac Surg 2019;14:183.

12. Grodzki T, Alchimowicz J, Kozak A, et al. Additional pulmonary resections after pneumonectomy: actual longterm survival and functional results. Eur J Cardiothorac Surg 2008;34:493-8.

13. Terzi A, Lonardoni A, Scanagatta $P$, et al. Lung resection for bronchogenic carcinoma after pneumonectomy: a safe and worthwhile procedure. Eur J Cardiothorac Surg 2004;25:456-9.

14. Spaggiari L, Grunenwald D, Girard P, et al. Cancer resection on the residual lung after pneumonectomy for bronchogenic carcinoma. Ann Thorac Surg 1996;62:1598-602.

15. Westermann CJ, van Swieten HA, Brutel de la Rivière A, et al. Pulmonary resection after pneumonectomy in patients with bronchogenic carcinoma. J Thorac Cardiovasc Surg 1993;106:868-74.

16. Levasseur P, Regnard JF, Icard P, et al. Cancer surgery on a single residual lung. Eur J Cardiothorac Surg 1992;6:63940; discussion 641.

17. Kittle CF, Faber LP, Jensik RJ, et al. Pulmonary resection in patients after pneumonectomy. Ann Thorac Surg 1985;40:294-9.

18. Massard G, Wihlm JM, Morand G. Surgical management for metachronous bronchogenic cancer occurring after pneumonectomy. J Thorac Cardiovasc Surg 1995;109:597-600.

19. Testolin A, Favretto MS, Cora S, et al. Stereotactic body radiation therapy for a new lung cancer arising after pneumonectomy: dosimetric evaluation and pulmonary toxicity. Br J Radiol 2015;88:20150228.

20. Giaj Levra N, Filippi AR, Guarneri A, et al. Efficacy and safety of stereotactic ablative radiotherapy in patients with previous pneumonectomy. Tumori 2015;101:148-53.

21. Thompson R, Giuliani M, Yap ML, et al. Stereotactic body radiotherapy in patients with previous pneumonectomy: safety and efficacy. J Thorac Oncol 2014;9:843-7.

22. Simpson DR, Sanghvi P, Sandhu AP. Lung stereotactic body radiotherapy for early-stage NSCLC in patients with prior pneumonectomy: a case report. J Natl Compr Canc Netw 2014;12:1513-6.

23. Senthi S, Haasbeek CJ, Lagerwaard FJ, et al. Radiotherapy for a second primary lung cancer arising postpneumonectomy: planning considerations and clinical outcomes. J Thorac Dis 2013;5:116-22.

24. Sofocleous CT, May B, Petre EN, et al. Pulmonary thermal ablation in patients with prior pneumonectomy. AJR Am J Roentgenol 2011;196:W606-12.

25. Hess A, Palussière J, Goyers JF, et al. Pulmonary radiofrequency ablation in patients with a single lung: feasibility, efficacy, and tolerance. Radiology 2011;258:635-42.

26. Haasbeek CJ, Lagerwaard FJ, de Jaeger K, et al. Outcomes of stereotactic radiotherapy for a new clinical stage I lung cancer arising postpneumonectomy. Cancer 2009;115:587-94.

27. Arifin AJ, Al-Shafa F, Chen H, et al. Is lung stereotactic ablative radiotherapy safe after pneumonectomy?-a 
systematic review. Transl Lung Cancer Res 2020;9:348-53.

28. Kozower BD, Larner JM, Detterbeck FC, et al. Special treatment issues in non-small cell lung cancer: Diagnosis and management of lung cancer, 3rd ed: American College of Chest Physicians evidence-based clinical practice guidelines. Chest 2013;143:e369S-99S.

Cite this article as: Yu X, Gao S, Xue Q, Tan F, Gao Y, Mao Y, Wang D, Zhao J, Li Y, Wang F, Cheng H, Zhao C, Yang D, $\mathrm{Mu}$ J. Therapeutic options for resectable second lung tumor after previous pneumonectomy: a SEER database analysis. Ann Palliat Med 2021;10(2):1866-1879. doi: 10.21037/apm-20-1781 
Table S1 Comparison of clinicopathological variables between the SLR group and lobectomy group

\begin{tabular}{|c|c|c|c|}
\hline Variables & $\operatorname{SLR}(n=62)$ & Lobectomy $(n=14)$ & $P$ value \\
\hline Age at pneumonectomy (years), mean \pm SD & $63.45 \pm 9.22$ & $67.14 \pm 10.58$ & 0.192 \\
\hline Age at SLT (years), mean \pm SD & $63.06 \pm 9.57$ & $65.86 \pm 10.16$ & 0.333 \\
\hline Female sex, $\mathrm{n}(\%)$ & $26(41.9)$ & $3(21.4)$ & 0.262 \\
\hline Race, n (\%) & & & 0.027 \\
\hline White & $61(98.4)$ & $11(78.6)$ & \\
\hline Black & $1(1.6)$ & $2(14.3)$ & \\
\hline Other & $0(0.0)$ & $1(7.1)$ & \\
\hline Interval time between pneumonectomy and SLT (months), mean \pm SD & $44.85 \pm 37.94$ & $22.24 \pm 33.24$ & 0.043 \\
\hline Left-sided pneumonectomy, n (\%) & $38(61.3)$ & $10(71.4)$ & 0.553 \\
\hline Histology of pneumonectomy, n (\%) & & & 0.687 \\
\hline Squamous cell carcinoma & $38(61.3)$ & $10(71.4)$ & \\
\hline Adenocarcinoma & $24(38.7)$ & $4(28.6)$ & \\
\hline Grade of pneumonectomy, $\mathrm{n}(\%)$ & & & 0.307 \\
\hline I, well & $2(3.2)$ & $2(14.3)$ & \\
\hline II, moderately & $22(35.5)$ & $3(21.4)$ & \\
\hline III, poorly & $27(43.5)$ & $8(57.1)$ & \\
\hline IV, undifferentiated & $3(4.8)$ & $0(0.0)$ & \\
\hline Unknown & $8(12.9)$ & $1(7.1)$ & \\
\hline Radiation with pneumonectomy, n (\%) & $14(22.6)$ & $2(14.3)$ & 0.745 \\
\hline CT with pneumonectomy, $\mathrm{n}(\%)$ & $16(25.8)$ & $4(28.6)$ & 0.832 \\
\hline TNM staging of pneumonectomy, $\mathrm{n}(\%)$ & & & 0.154 \\
\hline 1 & $14(22.6)$ & $2(14.3)$ & \\
\hline II & $22(35.5)$ & $2(14.3)$ & \\
\hline III & $24(38.7)$ & $8(57.1)$ & \\
\hline IV & $2(3.2)$ & $2(14.3)$ & \\
\hline Lymph nodes dissection, $\mathrm{n}(\%)$ & & & 0.153 \\
\hline Yes & $38(61.3)$ & $12(85.9)$ & \\
\hline No & $24(38.7)$ & $2(14.3)$ & \\
\hline Number of lymph nodes dissection, mean \pm SD & $11.71 \pm 10.27$ & $14.25 \pm 8.21$ & 0.440 \\
\hline Number of positive lymph nodes, mean \pm SD & $1.00 \pm 1.71$ & $2.92 \pm 3.40$ & 0.083 \\
\hline Histology of SLT, n (\%) & & & 0.513 \\
\hline Squamous cell carcinoma & $15(24.2)$ & $9(64.3)$ & \\
\hline Adenocarcinoma & $34(54.8)$ & $3(21.4)$ & \\
\hline Neuroendocrine tumor & $5(8.1)$ & $0(0.0)$ & \\
\hline Adenosquamous carcinoma & $2(3.2)$ & $0(0.0)$ & \\
\hline Other/unknown & $6(9.7)$ & $2(14.3)$ & \\
\hline Grade of SLT, n (\%) & & & 0.512 \\
\hline I, well & $8(12.9)$ & $1(7.1)$ & \\
\hline II, moderately & $19(12.9)$ & $5(35.7)$ & \\
\hline III, poorly & $25(40.3)$ & $4(28.6)$ & \\
\hline IV, undifferentiated & $2(3.2)$ & $0(0.0)$ & \\
\hline Unknown & $8(12.9)$ & $4(28.6)$ & \\
\hline Tumor size of SLT, mean \pm SD & $27.86 \pm 13.88$ & $27.81 \pm 13.74$ & 0.991 \\
\hline TNM staging of SLT, n (\%) & & & 0.037 \\
\hline I & $49(79.0)$ & $6(42.9)$ & \\
\hline II & $3(4.8)$ & $3(21.4)$ & \\
\hline (c) Alhnals of Palliative Medicine. All rights reserved. & $7(11.3)$ & http://dx.đ3oi21.0rg) 10.210 & pm-20-1781 \\
\hline IV & $3(4.8)$ & $2(14.3)$ & \\
\hline Type of SLT, n (\%) & & & 0.371 \\
\hline Metastasis & $25(40.3)$ & $8(57.1)$ & \\
\hline Metachronous & $37(59.7)$ & $6(42.9)$ & \\
\hline Radiation with SLT, n (\%) & $18(29.5)$ & $3(21.4)$ & 0.782 \\
\hline CT with SLT, n (\%) & $20(32.3)$ & $4(28.6)$ & 0.789 \\
\hline
\end{tabular}

SLR, sublobar resection; SD, standard deviation; SLT, second lung tumor; CT, chemotherapy; TNM, tumor-node-metastasis. 
Table S2 Univariate Cox regression analysis of patients who underwent surgical resection for SLT after previous pneumonectomy

\begin{tabular}{|c|c|c|c|c|c|}
\hline \multirow{2}{*}{ Variables } & \multirow{2}{*}{$\mathrm{N}$} & \multicolumn{2}{|l|}{ cSs } & \multicolumn{2}{|l|}{ os } \\
\hline & & 5 -year rate (\%) & $P$ value & 5 -year rate (\%) & $P$ value \\
\hline Age at SLT & & & 0.557 & & 0.210 \\
\hline$\leq 60$ years old & 27 & 61.2 & & 55.6 & \\
\hline$>60$ years old & 49 & 62.0 & & 52.0 & \\
\hline Sex & & & 0.121 & & 0.009 \\
\hline Female & 29 & 75.4 & & 69.0 & \\
\hline Male & 47 & 52.2 & & 43.3 & \\
\hline Race & & & 0.368 & & 0.375 \\
\hline White & 72 & 53.4 & & 62.3 & \\
\hline Black & 3 & 33.3 & & 33.3 & \\
\hline Other & 1 & 100.0 & & 100.0 & \\
\hline Interval time between pneumonectomy and SLT & & & $<0.001$ & & $<0.001$ \\
\hline$\leq 53$ months & 55 & 50.2 & & 41.5 & \\
\hline$>53$ months & 21 & 90.2 & & 85.2 & \\
\hline Histology of pneumonectomy & & & 0.891 & & 0.098 \\
\hline Squamous cell carcinoma & 48 & 62.7 & & 58.1 & \\
\hline Adenocarcinoma & 28 & 59.5 & & 44.9 & \\
\hline Grade of pneumonectomy & & & 0.185 & & 0.221 \\
\hline I-II & 29 & 48.9 & & 41.4 & \\
\hline III-IV & 38 & 68.2 & & 56.9 & \\
\hline Unknown & 9 & 77.8 & & 77.8 & \\
\hline Radiation with pneumonectomy & & & 0.448 & & 0.980 \\
\hline Yes & 16 & 61.9 & & 55.6 & \\
\hline No & 60 & 61.1 & & 52.7 & \\
\hline CT with pneumonectomy & & & 0.753 & & 0.275 \\
\hline Yes & 20 & 59.9 & & 58.1 & \\
\hline No/unknown & 56 & 67.4 & & 51.5 & \\
\hline TNM staging of pneumonectomy & & & 0.199 & & 0.991 \\
\hline I-II & 40 & 66.1 & & 54.5 & \\
\hline III-IV & 36 & 56.6 & & 51.8 & \\
\hline Laterality of SLT & & & 0.891 & & 0.098 \\
\hline Right & 48 & 62.7 & & 58.1 & \\
\hline Left & 28 & 59.5 & & 44.9 & \\
\hline Tumor size of SLT & & & 0.485 & & 0.166 \\
\hline$\leq 30 \mathrm{~mm}$ & 61 & 61.1 & & 51.8 & \\
\hline$>30 \mathrm{~mm}$ & 15 & 64.2 & & 59.3 & \\
\hline Histology of SLT & & & 0.458 & & 0.859 \\
\hline Squamous cell carcinoma & 18 & 67.8 & & 55.6 & \\
\hline Adenocarcinoma & 43 & 56.8 & & 47.5 & \\
\hline Neuroendocrine tumor & 5 & 40.0 & & 20.0 & \\
\hline Adenosquamous carcinoma & 2 & 100.0 & & 50.0 & \\
\hline Other/unknown & 8 & 62.5 & & 75.0 & \\
\hline Grade of SLT & & & 0.123 & & 0.482 \\
\hline $1-11$ & 33 & 60.6 & & 48.5 & \\
\hline III-IV & 31 & 71.8 & & 63.6 & \\
\hline Unknown & 12 & 41.7 & & 41.7 & \\
\hline TNM staging of SLT & & & $<0.001$ & & 0.001 \\
\hline I-II & 61 & 68.0 & & 59.9 & \\
\hline III-IV & 15 & 36.0 & & 26.7 & \\
\hline Lymph nodes dissection & & & 0.751 & & 0.416 \\
\hline Yes & 50 & 62.5 & & 56.0 & \\
\hline No & 26 & 60.5 & & 48.4 & \\
\hline Radiation with SLT & & & 0.016 & & 0.018 \\
\hline Yes & 21 & 56.2 & & 66.3 & \\
\hline No & 54 & 74.7 & & 49.2 & \\
\hline CT with SLT & & & 0.009 & & 0.001 \\
\hline Yes & 24 & 70.4 & & 70.4 & \\
\hline No/unknown & 52 & 57.3 & & 45.3 & \\
\hline Type of SLT & & & 0.019 & & 0.026 \\
\hline Metastasis & 33 & 50.1 & & 41.7 & \\
\hline Metachronous & 43 & 70.3 & & 62.1 & \\
\hline Surgical procedure of SLT & & & 0.030 & & 0.051 \\
\hline SLR & 62 & 65.8 & & 55.5 & \\
\hline Lobectomy & 14 & 42.9 & & 42.9 & \\
\hline
\end{tabular}


Table S3 Multivariate Cox regression analysis of patients who underwent surgical resection for SLT after previous pneumonectomy

\begin{tabular}{|c|c|c|c|c|}
\hline Variables & \multicolumn{2}{|l|}{ css } & \multicolumn{2}{|l|}{ OS } \\
\hline \multicolumn{5}{|l|}{ Sex } \\
\hline Male & & & Reference & \\
\hline Female & & & $0.346(0.172-0.694)$ & 0.003 \\
\hline \multicolumn{5}{|c|}{ Interval time between pneumonectomy and SLT } \\
\hline$>53$ months & Reference & & Reference & \\
\hline$\leq 53$ months & $6.157(1.849-20.504)$ & 0.003 & $4.617(1.912-11.148)$ & 0.001 \\
\hline \multicolumn{5}{|c|}{ TNM staging of SLT } \\
\hline III-IV & Reference & & Reference & \\
\hline Yes & Reference & & Reference & \\
\hline No & $0.832(0.295-2.347)$ & 0.728 & $0.848(0.378-1.905)$ & 0.690 \\
\hline \multicolumn{5}{|l|}{ CT with SLT } \\
\hline Yes & Reference & & Reference & \\
\hline No/unknown & $3.912(1.419-10.785)$ & 0.008 & $4.384(1.867-10.293)$ & 0.001 \\
\hline \multicolumn{5}{|l|}{ Type of SLT } \\
\hline Metachronous & Reference & & Reference & \\
\hline Metastasis & $1.378(0.663-2.865)$ & 0.728 & $1.222(0.660-2.261)$ & 0.523 \\
\hline
\end{tabular}

SLT, second lung tumor; CSS, cancer-specific survival; OS, overall survival; HR, hazard ratio; Cl, confidence interval; CT, chemotherapy; TNM, tumor-node-metastasis; SLR, sublobar resection. 